\title{
MOBILIDADE URBANA E CIDADANIA EM DOIS CONTOS DE FERRÉZ
}

Marcus Rogerio Tavares Sampaio Salgado (UFRJ)

Resumo: O objetivo do presente artigo é o estudo das representações ficcionais da mobilidade urbana em dois contos do escritor paulistano Ferréz, "O grande assalto" e "Terminal (nazista)". Ambos fazem parte de Ninguém é inocente em São Paulo, volume de contos publicados em 2006 e que apresenta, como as demais obras do escritor, ambientação urbana e cenas que podem funcionar como ponto de partida para importantes debates sobre as relações diretas entre mobilidade urbana e cidadania.

Palavras-chave: Literatura brasileira contemporânea; Literatura marginal-periférica; Mobilidade urbana; Cidadania.

Abstract: This article aims at analising fictional mimesis of urban mobility in Ferréz's two tales - "O grande assalto" and "Terminal (nazista)". Both were published in Ferréz's 2006 book Ninguém é inocente em São Paulo. The aforementioned collection of tales present, as his other works, urban ambience and fictional scenes that can be used as a point of departure for further discussions on the relations between citizenship and urban mobility.

Keywords: Contemporary Brazilian literature; Fringe literature; Urban mobility; Citizenship.

Composto por dezoito contos e uma espécie de prefácio (intitulado de "Bula"), todos eles bastante curtos, Ninguém é inocente em São Paulo (2006) recolhe algumas das incursões do autor fora do gênero romance, com o qual havia se notabilizado desde Capão Pecado. Segundo o próprio Ferréz, muitos desses contos são "trechos de vida que catei" (2006, p.10), quando não "histórias diversas do mesmo ambiente, 
um país chamado periferia" (2006, p.10) - de forma que "a maioria era inédita no papel, mas não vida" $(2006$, p.10).

Como ocorre em outras obras do escritor, o cotidiano e as práticas sociais das populações periféricas de São Paulo são focalizados nos dezoito contos, ressaltando-se a questão da mobilidade urbana e suas relações com a cidadania. A questão se encontra presente em pelo menos sete contos do livro: "O plano", "O grande assalto", "Pão doce”, “Era uma vez", "O ônibus branco", "Assunto de família" e "Terminal (nazista)".

Levando-se em consideração que "a condição de mobilidade nas cidades tornou-se um dos maiores problemas sociais e urbanos" (MARICATO, 2015, p.42), uma vez que uma complexa trama de relações socioeconômicas, culturais e antropológicas se estabelece em seu interior, focalizaremos nos contos "O grande assalto" e "Terminal (nazista)", pelo fato de que neles as questões relativas à mobilidade urbana e à cidadania ocupam papel estruturante.

\section{A DIALÉTICA DO DESPREZO E DO RECONHECIMENTO}

O conto "O grande assalto" é todo estruturado a partir de coordenadas espaciais e posições específicas tomadas no espaço urbano pelos actantes da narrativa.

Já no primeiro parágrafo é apresentado o cenário do conto, com uma referência toponímica bem particular: 
a avenida Santo Amaro. Importante via de São Paulo, ela é responsável pela ligação da zona sul (região mais populosa, territorialmente mais extensa e com diversos bairros ocupando as posições mais baixas na lista dos índices locais de desenvolvimento humano da cidade) com o centro. Essa via de alta circulação é testemunha das profundas transformações urbanísticas que a cidade passou na segunda metade do século $X X$, com a expansão da mancha urbana no sentido da periferia e o consequente adensamento demográfico, ambas agravadas pela escolha do modelo rodoviário em matéria de mobilidade urbana. Afinal, com frequência a referida avenida teve a seu nome associado ao trânsito moroso provocado por filas de automóveis e, sobretudo, ônibus - já que, até a construção da linha cinco do metrô, essa era a principal forma de transporte para uma parte significativa da população da zona sul. Além disso, a avenida Santo Amaro se estende por um território mosaicado, que a transforma também em paisagem cultural: ela se estende até o Largo Treze (importante região da cidade para a vivência de tradições culturais dos migrantes nordestinos), hospedando em seu percurso tanto luxuosas concessionárias de automóveis como a famosa Estátua do Borba Gato, considerada, a despeito do orgulho bandeirante, o monumento público mais feio da cidade. Pode ser enquadrada, com facilidade, no conceito urbanístico 
que contempla as chamadas vias arteriais - assim definidas: "como analogia do sistema vascular do corpo humano, são chamadas assim aquelas "artérias" que percorrem grandes distâncias, têm maior largura e por esses dois motivos servem um tráfego mais volumoso" (VASCONCELOS, 2018, p.77) -, pois a avenida Santo Amaro serve as vezes de conduto para quem desejar chegar a bairros tanto de classe média alta (como a Vila Nova Conceição, Moema e Brooklyn) como para a periferia.

A seguir, entram em cena os actantes, em suas posições territoriais específicas.

O primeiro deles é o homem malvestido. Ele se encontra ao rés do chão, em frente a uma concessionária de automóveis fechada. Situado ao nível da rua, e a ela fixado na narrativa (em pé, sonhando; ou caído, abatido - literalmente), o homem malvestido representa uma posição sistêmica bem específica, na qual se amalgamam a precariedade econômica e a vulnerabilidade social. Essa posição sistêmica (expressa no texto pelo posicionamento do primeiro actante ao rés do chão) é confirmada com a entrada em cena do segundo actante. É um policial, que, ao sair do interior de sua viatura, observa o homem malvestido e, a partir de seu ponto de visão, identifica-o como suspeito. Instaura-se entre eles uma relação topográfica, na qual as posições no espaço 
físico podem coincidir ou não com as posições sistêmicas. Embora estejam ambos ao nível da rua (o que pressuporia uma relação de frontalidade), o olhar lançado pelo policial em direção ao homem malvestido se dilata em uma relação agressiva e judiciosa impregnada de verticalidade. Isso é reforçado pelo uso do verbo descer, que é um dos "verbos de orientação vertical" (BORGES FILHO, 2007, p.135), pelos quais se engendra um eixo vertical de movimentação e de olhar. Assim, se no espaço físico o homem malvestido e o policial ocupam posição simétrica, tal simetria não se realiza também ao nível do olhar, que é marcada pela verticalidade opressiva característica do modo de divisar o mundo dos agentes de controle social a serviço do estado. Divisar, portanto, é ver (implícito no ato de visar), dividir (implicando acima de tudo uma partilha do mundo empírico na qual estariam pré-definidos os lugares e os sujeitos desses lugares) e estabelecer uma fronteira territorial de guarda e salvaguarda.

A função do policial a postos em sua viatura é a de "pacificação do espaço público" (SLOTERDIJK, 2002, p.43), o que é obtido mediante o controle social dos fluxos, deslocamentos e presenças. Se, por um lado, para a urbe lugar de encontro de indivíduos e culturas distintas quando 
não distantes - organização e controle funcionam "como fundamento de sua existência" (VERÍSSIMO et al, 2001, p.57), por outro não há como refutar o fato de que "as elites sempre tentaram, juntamentecomo poder, exercerformas de controle sobre os demais, sobre a circulação alheia, especialmente do povo comum" (VERÍSSIMO et al, 2001, p.59). Vale lembrar que o policial está a postos em um lugar bastante próximo à concessionária de carros importados, confundindo-se, portanto, nessa posição assumida por ele no espaço físico, as funções de controle dos fluxos, deslocamentos e presenças e de salvaguarda da propriedade privada. É assim que, se o estado detém o monopólio da violência (rotineiramente utilizada para defesa da propriedade), a esse agente postado junto à concessionária é delegado esse monopólio da força, verificando-se aí uma cadeia de transmissão de tipo vertical. Pela lógica do monopólio estatal da violência, o policial recebe sobre si o mesmo impacto dessa força vertical que ele aplica sobre os corpos que se deslocam pela urbe, padecendo, também, do mesmo tipo de redução antropológica da individualidade (SLOTERDIJK, 2002, p.44) que a dos corpos a que deve submeter a partir dessa lógica redutiva. Cabe a ele reconhecer ou desprezar o direito à cidade e à livre mobilidade, ao reproduzir como uma equação os elementos decisivos dessa lógica redutiva em situações 
empíricas; neste gesto esvaziado de potência subjetiva, no interior do qual se encontra apenas a força vertical da violência como prerrogativa e como exercício que se satisfaz em si mesma, fica claro como "desprezíveis parecem aqueles desprezadores embotados contra todo movimento que ultrapasse valorações, desejos e procedimentos de compreensão do centro auto-satisfeito" (SLOTERDIJK, 2002, p.68). Se em suas decisões e gestos de reconhecimento o agente pode transportar para uma faixa inferior (que, a partir da perspectiva vertical, tornam-se quase invisíveis a quem ocupa as posições superiores, em uma operação de reengenharia do olhar social) da vida coletiva da urbe, isso não o impede de, nesse gesto de negar reconhecimento à cidadania (quando não à própria humanidade) do outro, também a si mesmo desumanizar-se, sob a coerção da mesma cadeia de comunicação vertical. Essa perda da humanidade pelo agente parece ser reforçada por uma estratégia de atuação robotizada, com gestos padronizados e o uso desproporcional da violência; além disso, o modo como se põe em relação a sua viatura um pouco à maneira com que um ciborgue dispõe de seus componentes maquínicoextensionais. Que a máquina é uma extensão da libido, já sabia Marshall McLuhan desde The mechanical bride, e não é preciso ter lido o pensador norte-americano para perceber 
"o conforto e o fetiche representado pelo automóvel" (MARICATO, 2015, p.43); no entanto, aqui a máquina não é só isso, funcionando antes como uma extensão do Super Ego, pela qual se ratifica a "prioridade indiscutivel que é dada ao automóvel na matriz urbana" (MARICATO, 2015, p.46) - o que se torna tanto mais explícito se lembrarmos que essa prioridade, embora verificável empiricamente com grande facilidade, "não está afirmada em nenhum documento, discurso ou plano" (MARICATO, 2015, p.46-47).

Se todos são iguais perante a lei, alguns, no entanto, não podem circular em certos territórios ou simplesmente sua presença pode significar uma ameaça à manutenção da propriedade privada e da ordem social. Na relação espacial que se desenha entre o homem malvestido e o policial que sai da viatura para uma operação de reconhecimento resta explícito aquilo que Peter Sloterdijk identifica como "problema nevrálgico da sociedade moderna: o conflito entre horizontalidade e verticalidade" (2002, p.78), já que, para o filósofo alemão, a comunicação vertical implica exatamente um gesto ofensivo.

Ao mesmo tempo em que princípios jurídicoconstitucionais afirmam o direito de ir e vir, no mundo empírico a função do policial é decidir e controlar quem pode circular por aquele território do espaço urbano, explicitando 
a existência de "normas escritas e não escritas associadas ao controle social" (VERÍSSIMO et al, 2001, p.58). Em última instância, a partir de sua posição no espaço físico que reflete uma posição na sociedade de classes, a tarefa do policial junto à concessionária de carros importados é uma questão de reconhecimento: cabe a ele reconhecer que corpos devem ou não circular pelo território sob seu controle delegado. Se é verdade que "um desprezo de todos por todos infiltra-se nas premissas da doutrina política moderna do homem" (SLOTERDIJK, 2002, p.49) e que vivemos em formações sociais tensionalmente vinculadas sob a força de "um Estado potencialmente assassino de todos" (SLOTERDIJK, 2002, p.47), a recusa ou a concessão de reconhecimento pelos agentes a serviço do monopólio da violência faz com que uma parte da população deslize para uma posição sistêmica em que precariedade econômica e vulnerabilidade social são equalizados e sua presença no mundo se concentra na disputa pela própria existência física, contra o desprezo, o aniquilamento e o extermínio.

O homem malvestido experiencia uma situação social que é antipódica à de outro actante, o jovem universitário no interior de seu carro. O jovem ostenta uma situação de aparente simetria com o policial, pois ambos deslocam-se pelas vias 
da cidade não como pedestres e sim com a mediação de um veículo. Esse veículo não apenas assegura melhores condições de mobilidade urbana que à da média dos habitantes da urbe (subordinados ao interior do transporte coletivo, sempre lotado e impontual) como ainda pode funcionar como endosso de uma posição relativamente privilegiada na sociedade de classes. Afinal, ao deparar-se com uma interrupção do fluxo pelo sinal, pelo ônibus e pela presença de policiais, sente-se desconfortável - e não é apenas pelo fato de carregar consigo substâncias ilegais: seu deslocamento é feito por um meio de transporte individual e privado, para o qual são extensas as demonstrações no espaço urbano "da força da ideia do automóvel como um bem muito importante" (VASCONCELOS, 2018, p.76), uma vez que a própria malha viária parece ter sido traçada de forma a privilegiar esse meio de transporte, razão pela qual sua demanda é por "fluidez e microacessibilidade nos endereços de destino" (VASCONCELOS, 2018, p.76). E é neste ponto que a narrativa de Ferréz apresenta suas sutilezas de estruturação: não sabemos, em fim de contas, se o jovem é invisibilizado no campo de visão dos policiais por conta de um processo imediato de reconhecimento de sua cidadania por parte dos agentes legais de controle social ou se a concêntrica obsessão higienista de retirada de circulação dos "feios, sujos e malvados" - ou pelo menos 
aqueles corpos assim identificados pelo olhar estruturado a partir da lógica do monopólio da violência-o tornou invisível, paralelamente ao que ocorre com o homem malvestido, espancado brutal e sumariamente pelos mesmos agentes que ignoram o criminoso e a situação potencialmente criminosa acondicionados no interior de um veículo particular. À escolha por uma ou outra resposta a esse ponto nodal da narrativa independe a constatação, armada em traços rápidos pela prosa urbana de Ferréz (um pouco à maneira da aplicação do spray de tinta sobre os muros da cidade), de como mobilidade e cidadania se encontram intimamente ligados.

A ausência de simetria entre posições e a tensão entre os pares dialéticos do reconhecimento e do desprezo atingem o ponto de saturação nas cenas da breve narrativa que se desenrolam no interior de um ônibus.

O primeiro ponto é a constatação de que o cotidiano, quando transposto para o âmbito da mimese artística, pode resultar paradoxal: se a concepção de espaço arraigada no senso comum é a de algo estático e estável, ainda que atravessado pela historicidade, ou mesmo natural, não deixa de causar surpresa que o espaço cenográfico seja deslocado para o interior de um dispositivo semovente - portanto, 
para o interior de um espaço que não pode ser compreendido como estático e estável. À maneira de um jogo de caixas embutidas, o segundo paradoxo é que, para a animação da cena, esse espaço cenográfico semovente encontra-se parado - e, nessa pausa, coagulados o tráfego e, em alguma medida, o próprio espaço.

No interior dessa coagulação topológica, abre-se o ônibus como uma bolha, oferecendo um ponto de vista privilegiado em relação ao jogo cênico. Ao motorista e aos passageiros no interior do ônibus abrem-se duas possíveis orientações de olhar, ambas de frontalidade. A primeira está ligada ao fato de que o ônibus está parado diante de um semáforo: essa orientação frontal do olhar é dominante para o motorista. A segunda está, por sua vez, ligada ao fato de que os passageiros (tanto os sentados como os que estão em pé) têm diante de si o desenrolar de uma cena, que será, inclusive, interpretada individualmente, em consonância ou não com sua posição sistêmica. A posição dos passageiros no interior do ônibus também é ambivalente: em relação ao espaço físico, ainda se deslocam ao nível do chão, mas seu olhar é erguido em orientação verticalizante pelo chassis do veículo, permitindo uma vista que se perfaz um pouco acima do chão, em direção ao que está abaixo. Com exceção dos passageiros 
que estão em pé (esses em relação de frontalidade), a perspectiva vertical que se oferece no interior do ônibus em relação à cena não é ortogonal, mas sim diagonal, revestindo-se ainda de uma lateralidade que engendra pontos de visão a partir de ângulos obtusos (e aqui resta explícita a correlação direta entre ponto de vista empírico e posição sistêmica, dado o significado que a palavra obtuso pode assumir, associado à turvação ou mesmo incapacidade de compreensão dos fatos).

O ônibus parado diante do sinal - e da cena - possibilita aos passageiros uma visão da cidade como espetáculo. Diante de seus olhos, os passageiros têm um palco (ou ringue) sobre o qual um policial aborda e espanca um homem malvestido com balões. Nessa encenação da vida pública que se abre no asfalto, os actantes são identificados e codificados pelos passageiros a partir de categorias antinômicas terrivelmente marcadas pela redução antropológica. Assim, o policial é identificado como o herói e com os valores positivos e o homem malvestido como o vilão e com os valores negativos. Se a posição dos passageiros é ambivalente, sua reação, como se percebe, é monocromática. Quem primeiro alerta é uma senhora sentada, que percebe a cena e reconhece o potencial espetacular que a mesma tem - afinal, se no nível 
da superfície a senhora apenas adverte da presença de um homem sujo em frente à concessionária, em um território mais fundo e pantanoso da enunciação ressoa o sinal de detecção de um contraste socioeconômico incontornável, sobretudo quando a miséria é criminalizada e sua presença e circulação pelo corpo da urbe são interditados. A esse estímulo inicial, reage a moça sentada ao lado, que, a seguir, ratifica a equalização entre miséria e crime esperada pelo código ideológico em processamento, chamando a atenção de outros passageiros. Como o desfecho de uma cena ou mesmo o último capítulo de uma novela, o motorista sente que não pode perder o que se está a desenrolar e "tenta ficar com o ônibus parado para ver os policiais darem chutes e socos em um homem malvestido que está caído na calçada" (FERRÉZ, 2006, p.24). Reafirma-se, na reatividade passiva da plateia diante da desproporcionalidade entre o possível ilícito e a resposta dos agentes, diante da abordagem fora dos padrões técnicos prescritos pela própria polícia e diante da patente violação de direitos a que o outro é submetido, o escopo de controle social que se encontra no núcleo do espetáculo. O que os passageiros têm diante dos olhos é um espetáculo didático, que chega mesmo a romper com a quarta parede para ensinar a cada um seu lugar no espaço físico e sua posição sistêmica, e produzir uma prova 
incontestável de como as relações sociais estão envolvidas pelo cotidiano, uma vez que é nele que se dão as demandas e os embates por reconhecimento.

Sob a lógica do espetáculo, os actantes em “O grande assalto" parecem mergulhados "num individualismo característico do desmantelamento dos laços sociais e de desengajamento" (PECHMAN, 2014, p.30), simbolizando a crise daquilo que Robert Pechman chama de "convivialidade" (2014, p.19) - fator diretamente ligado à experiência urbana. Segundo Pechman (2014, p.19), "quanto menos convivialidade, tanto menos urbanidade. Tanto menos urbanidade, quanto mais violência". Entre os polos dialéticos do desprezo e do reconhecimento, sustenta-se, fragilmente, essa convivialidade. E a reação dos actantes em "O grande assalto" reproduz, em escala micro, o paradigma social mais amplo pelo qual "os direitos de propriedade privada e as taxas de lucro se sobrepõem a todas as outras noções de direitos em que se possa pensar" (HARVEY, 2014, p.27) - e tudo o mais não é mais que isso: resto, sobra, resíduo. O não reconhecimento do outro não apenas o reifica, como ainda o transforma em dejeto, objeto indesejável, de circulação proibida na cidade idealizada pelos poderes públicos comprometidos com a ordem econômica. Nada mais consequente que a urbanização assimile esse paradigma mais 
amplo da sociedade, afinal "produzindo cidades-modelos, funções-modelos, conjuntos artificiais, produz-se todo o resto como dejeto, como detrito, como vestígio inútil" (BAUDRILLARD, 1994, p.33).

Em última instância, "O grande assalto" pode ser lido como a representação daquilo que entre os teóricos da mobilidade urbana se identifica como "conflito de circulação" (VASCONCELOS, 2018, p.44). Tais conflitos podem ser de duas ordens: a primeira, física, concernente à engenharia de tráfego; a segunda, política, quando se revelam por trás dos conflitos "os interesses e as necessidades dos diferentes papéis em cada sociedade" (VASCONCELOS, 2018, p.47). Assim, o que parece apenas uma questão prosaica de controle de fluxos e presença com fins de manutenção da ordem social e da propriedade privada revela-se, em fim de contas, como a representação de um conflito com dimensões políticas, pelo qual restam explícitas as desigualdades no uso do espaço urbano, já que, embora garantido pelo estatuto jurídico o direito de ir e vir, nem todos são contemplados com posições simétricas em relação ao exercício da prerrogativa do direito à cidade.

\section{ENTRE UM TERMINAL E OUTRO}

Como ocorre com qualquer "ultracidade monstruosa" (NANCY, 2013, p.18), é difícil escolher uma imagem da 
cidade de São Paulo que por si baste em termos de representação icônica da mesma. A constituição mosaicada do tecido urbano colabora, de forma decisiva, para a impossibilidade dessa representação sintética. Afinal, no lugar dessa representação única e inequívoca, o que temos é um conjunto de imagens representativas dessa paisagem urbana, no qual encontraremos edifícios, muralismo, grafite, pichação, postes elétricos, vitrines, imagens publicitárias, monumentos etc. Da mesma forma com que, a rigor, para a constituição desse conjunto de imagens, concorrem tanto o moderno quanto o pré-moderno e o pós-moderno, também se farão presentes não apenas os lugares, como também os não-lugares.

Neste sentido, o Terminal Bandeira pode ser considerado um exemplo de não-lugar que colabora na composição de uma imagem desse tecido urbano coletivo. O terminal de ônibus fica na Praça da Bandeira, ponto de interseção entre as avenidas 9 de Julho e 23 de Maio, duas importantes vias arteriais. Juntamente com o Terminal Parque Dom Pedro II, o Terminal Bandeira é dos mais importantes, tanto pelo intenso fluxo de passageiros (que, segundo o site da $S P$ Trans, chegaria ao número de cento e trinta mil pessoas por dia) como pelo fato de conectar o centro com a zona sul. 
Como já apontou Marc Augé, encontram-se entre os exemplos mais patentes de não-lugares justamente "os pontos de trânsito e as ocupações provisórias" (2012, p.74). Assim, além de enquadrar-se facilmente na tipologia proposta pelo antropólogo francês (ao lado dos aeroportos e das estações de transporte de um modo geral), também o Terminal Bandeira - resultado de transformações radicais na paisagem urbana na segunda metade do século $X X$ - se distancia dos chamados "lugares de memória" (2012, p.73). Sua existência, a bem da verdade, é recente e polêmica, dado que, em 2011, no âmbito do concurso de urbanismo "A Cidade somos nós: propostas para a São Paulo de 2030", o projeto premiado, assinado pelos arquitetos José Paulo de Bem, Fernanda Haddad e Cássia Mariano, propunha nada menos que a extinção do terminal.

Pelo fluxo intenso e pelo impacto ambiental a ele ligado, não seria exagero dizer que os terminais de ônibus sintetizam a potencialidade do espaço urbano como "lugar ao mesmo tempo de conexão, coagulação e difração" (NANCY, 2013, p.10). É a partir dessa tríplice função que o terminal de ônibus é representado no conto "Terminal (nazista)", com que Ferréz encerra o volume de contos Ninguém é inocente em São Paulo. 
O conto registra aquilo que é uma cena prosaica na vida dos moradores de São Paulo: o deslocamento de um terminal a outro da cidade. O ponto de partida, embora não haja referências toponímicas, provavelmente situa-se na zona sul, ao passo que o ponto de chegada é justamente o Terminal Bandeira.

Situados em pontos distantes da cidade, o percurso entre os dois terminais ilustra bem as relações mercuriais que coordenam a mobilidade em uma megalópole. Há uma demanda, por cada habitante da cidade, por deslocamento e ela deve ser enquadrada dentro da malha de transportes e das estratégias de mobilidades existentes ou oferecidas. A convergência e a vinculação entre demanda e oferta, contudo, não é facilmente resolvida, pois, em princípio, "os terminais servem para as pessoas fazerem baldeação para atingir os destinos finais" (VASCONCELLOS, 2018, p.177); no entanto, "esta troca não é desejada pelas pessoas - que poderiam ter linhas diretas ligando sua origem ao seu destino - mas pode tornar-se necessária para otimizar o sistema de transporte da cidade e para viabilizar ligações que não comportariam uma linha direta" (Vasconcellos, 2018, p.177). Além disso, "o transporte público envolve uma socialização da infraestrutura (vias) e dos meios de transporte (veículos)" 
(Vasconcellos, 2018, p.35). Desse modo, para que a conexão se realize, são, por vezes, necessárias estratégias difrativas, que estejam em observância não apenas as políticas públicas de garantia da mobilidade como também as condições empíricas pelas quais se dá o deslocamento.

O deslocamento para a qual embarcam os passageiros em "Terminal (nazista)" pode durar um par de horas e é feito em situações adversas, uma vez que as baixas oferta e qualidade do transporte público, aliadas a seu custo, interferem diretamente nas condições de mobilidade. É assim que uma viagem entre os dois terminais - como a que os actantes de "Terminal (nazista)" estão embarcando-acaba porterum impactofísico epsicológico imenso nos usuários do transporte coletivo. Duas horas dentro de um veículo sem ar condicionado, ruidoso, poluente e lento demonstram, de forma cabal, como "a circulação está ligada aos fatores de mobilidade e acessibilidade" (VASCONCELLOS, 2018, p.35). Mais uma vez fica claro como "a liberdade para ir e vir nas metrópoles é diretamente proporcional ao acesso que cada indivíduo tem aos meios de transporte e circulação na cidade" (Vasconcellos, 2018, p.55). Ou seja: se todos têm direito à cidade e sua mobilidade garantida por lei, o exercício de fato dessa prerrogativa está condicionado a fatores socioeconômicos. 
Mas o sofrimento ao deslocar-se que sofrem os actantes de "Terminal (nazista)" não se dá apenas ao longo de uma viagem cansativa e em condições extremas de estresse ambiental. A bem da verdade, ela começa antes de o ônibus começar a circular, já no espaço de acesso aos veículos no interior do terminal. Ali dentro, organizadores de fila se ocupam com o controle da circulação dos corpos e seu ordenamento em obediência a regras de mobilidade bem precisas. Para que o espaço urbano exerça sua força de catálise, é necessária a ordenação dos corpos em padrões quefacilitem os fluxos. Ocorre, literalmente, um processo de coagulação dos passageiros: de fluxo incerto, caótico e líquido, são transformados em massa, em corpo sólido manipulável. Para tanto, os passageiros são reificados e, nesse processo de desumanização, tratados como objetos pelos organizadores de fila. A cena em que um passageiro tenta aproveitar-se do traçado indefinido de uma fila de espera muito longa é emblemática neste sentido: “Um dos organizadores o agarrou pelo ombro e o jogou para longe" (FERRÉZ, 2006, p.89).

A atuação dos organizadores de fila não é muito diferente da que preside os atos do policial em "O grande assalto". Cabe aos organizadores a tarefa de reconhecimento - e não é sem motivo que observam desconfiados qualquer 
passageiro com movimentação pouco comum ou fora dos protocolos de controle social (caso do próprio narrador, que se vê assim olhado ao movimentar-se na fila) - e, de igual forma, um e outro têm seus atos motivados por uma "visão securitária e higienista do espaço urbano" (ROLNIK, 2017, p.99). Por essa visão, as questões concernentes à mobilidade urbana e à circulação não são tratadas em sua complexidade, sendo antes reduzidas "simplesmente à constatação da presença ou não das pessoas em determinados espaços públicos" (ROLNIK, 2017, p.99).

$\mathrm{Na}$ fila do ônibus, prestes a embarcarem em uma áspera viagem de duas horas, reúnem-se os passageiros, desumanizados pela brutalidade do controle dos organizadores, pela precariedade do transporte oferecido e pelas pressões sistêmicas que acachapam sua existência. Como ressalta Robert Pechman (2014, p.128), "todos os afetos estão na cidade. Ódios, paixões, vergonhas, compaixões, ressentimentos, desejos". O narrador parece atento a isso e não deixa de reparar que a fila não é apenas uma sequência de pessoas - ela representa, por si, mais um desfile diário do bloco dos humilhados e ofendidos: “Problema com filho, problema com aluguel, problema por ter muito problema. Eu tentava olhar diretamente para os olhos, os que não tinham a cabeça muito baixa não tinham globos oculares" (FERRÉZ, 2006, p.89). 
Como ocorre com o olhar indiferente do motorista e dos passageiros dentro do ônibus em "O grande assalto", os globos oculares vazios parecem remeter àquilo que Eliana Kuster (2014, p.103) chama de "olhar sem alma", resultado de uma indiferença socialmente programada. Cabisbaixa, a massa de passageiros - e "alguns sacavam máquinas dos bolsos, falavam com elas, escutavam elas" (FERRÉZ, 2006, p.90) - desse conto prenuncia as representações dos deslocamentos nas ultracidades monstruosas que encontramos em um filme como O Congresso Futurista (2013), no qual, em um cenário distópico marcado pela automação e pela desvalorização do elemento humano, estímulos químicos manteriam as populações em estado de inércia e proporcionariam a vivência de fantasias consumistas ao nível das práticas cotidianas, incluindo aí não apenas a modelagem da identidade social como também os deslocamentos pelo espaço urbano, em um questionamento das fronteiras entre realidade e alucinação.

Neste sentido, não é por acaso que o narrador diversas vezes se flagra desconfiando de seu verdadeiro destino: seria aquele realmente o ônibus a ser tomado? A percepção de passageiros sem os globos oculares aumenta o clima de incerteza quanto ao que é empiricamente percebido pelo narrador. É neste ponto que se desdobra a analogia a partir 
da qual o conto é todo construído: seriam os humilhados e ofendidos naquela fila desumana e desumanizadora os judeus de nosso tempo? Estariam eles - ali, de pé na fila, passivos ao controle dos organizadores, preparando-se para seguir rumo a seus empregos - na verdade destinados a uma forma lenta e inexorável de morte? Não por acaso os campos de concentração nazistas ostentavam em sua entrada o irônico bordão "O trabalho torna livre". De igual forma, os nazistas construíram toda uma rede de transportes para o holocausto. Nos trens, após uma triagem prévia com o fito de discriminação por critérios socioeconômicos, os corpos eram enfileirados e remetidos aos campos de concentração; ao desembarcarem, eram novamente separados e encaminhados às câmaras de gás. Para manter a ordem e a fluidez das operações, era mantida não apenas uma malha ferroviária, como também a atuação de soldados alemães, que, à maneira dos organizadores de fila, ordenavam os fluxos. Neste ponto ficam explícitas as referências contidas no título do conto de Ferréz: terminal é tanto um substantivo como um adjetivo, da mesma forma com que a fila, os organizadores e os transportes estabelecem uma relação de analogia direta com a barbárie nazista. 


\section{REFERÊNCIAS}

AUGÉ, Marc (2012). Não lugares: introdução a uma antropologia da supermodernidade. São Paulo: Papirus.

BAUDRILLARD, Jean (1994). "Conjuntos artificiais - A Biosfera 2 ou Da conjuração do mal até a gestão dos dejetos". Tempo Brasileiro, 116, p.27-37. FERRÉZ (2006). Ninguém é inocente em São Paulo. São Paulo: Objetiva.

HARVEY, David (2014). Cidades rebeldes: do direito à cidade à revolução urbana. São Paulo: Martins Fontes.

KUSTER, Eliana (2014). "O tédio dos olhares sem alma". In: PECHMAN, Robert; KUSTER, Eliana. O chamado da cidade: ensaios sobre a urbanidade. Belo Horizonte: Editora da UFMG.

MARICATO, Erminia (2015). Para entender a crise urbana. São Paulo: Expressão Popular.

NANCY, Jean-Luc (2013). La ciudad a lo lejos. Buenos Aires: Manantial.

PECHMAN, Robert (2014). "Quando Hannah Arendt vai à cidade...". In: PECHMAN, Robert; KUSTER, Eliana. O chamado da cidade: ensaios sobre a urbanidade. Belo Horizonte: Editora da UFMG.

ROLNIK, Raquel (2017). Territórios em conflito: São Paulo - espaço, história e política. São Paulo: Três Estrelas.

VASCONCELLOS, Eduardo Alcântara de (2018). Mobilidade urbana e cidadania. São Paulo: Senac.

Marcus Rogerio Tavares Sampaio Salgado é Doutor em Ciência da Literatura (UFRJ) e mestre em Literatura Brasileira (UFRJ), é Professor Adjunto de Literatura Brasileira (UFRJ), com atuação na graduação e na pós-graduação. Autor dos livros de ensaios $A$ arqueologia do resíduo (2013) e Vida vertiginosa dos signos (2007). Integra os Grupos de Pesquisa LABELLE (UERJ) e Estéticas de fim de século (UFRJ). E-mail: marcussalgado@gmail.com 